\title{
A STUDY OF PSYCHOPATHOLOGY, COPING AND QUALITY OF LIFE IN PARENTS OF CHILDREN DIAGNOSED WITH ACUTE LEUKAEMIA
}

\author{
M. Sophia1 , S. Ananda Krishna Kumar², G. A. Viswanathan³, S. Sabhesan 4 \\ ${ }^{1}$ Consultant Psychiatrist, Madurai. \\ ${ }^{2}$ Associate Professor, Department of Psychiatry, Madurai Medical College, Madurai. \\ ${ }^{3}$ Assistant Professor, Department of Psychiatry, Madurai Medical College, Madurai. \\ ${ }^{4}$ Retired Professor and HOD, Department of Psychiatry, Madurai Medical College, Madurai.
}

ABSTRACT

\section{BACKGROUND}

Parents are usually the obligatory decision makers for the child, and thus are involved in all aspects of his or her care. Serious illness or prolonged treatment often results in significant emotional distress to the parents, impairing their ability to provide the necessary support and care to the child. Parental helplessness, anger, withdrawal, over-protectiveness and other emotional factors should be factored in to evolve an appropriate therapeutic plan to address the emerging needs of both the children and their parents.

The present study aims to assess the psychopathology among the parents of children with ALL, their Family burden, Quality of life, stressful life events and coping and to infer their possible predictors.

\section{MATERIALS AND METHODS}

The present study aims to understand the psychological consequences on the parents of children diagnosed to have Acute Lymphoblastic Leukaemia, their coping skills and quality of life and their associations. Further the study also assesses the relationship of Family Burden, Stressful life events and Psychopathology.

\section{RESULTS}

Parents of children with ALL are more prone to Psychiatric disorders with Adjustment disorders being the most common Psychiatric illness among the parents. Duration of illness in children shows no relationship with Psychopathology and Quality of life in parents but development of side effects in treatment reduces overall Quality of life. The presence of stressful life events significantly increases the risk of Psychiatric disturbances with poor Quality of life in parents. Psychopathology and the quality of life do not show significant relationship with ways of coping except those who used distancing as a coping strategy found their social relationships to be poor. The presence of stressful life events and psychiatric disturbances significantly interferes Family dynamics, Family interaction and Subjective Burden.

\section{CONCLUSION}

Our conceptualisations of chronic illnesses are thus changing. In addition to focusing purely on the medical management of Leukaemia in the child, it would be worthwhile to focus attention on the extreme distress experienced by their parents. An empathic attitude towards their travails would go a long way in helping to reduce their distress.

\section{KEYWORDS}

Psychopathology, Quality of Life, Stress, Parents of Children, Leukaemia.

HOW TO CITE THIS ARTICLE: Sophia M, Kumar SAK, Viswanathan GA, et al. A study of psychopathology, coping and quality of life in parents of children diagnosed with acute leukaemia. J. Evolution Med. Dent. Sci. 2017;6(86):5941-5946, DOI: $10.14260 /$ jemds/2017/1293

\section{BACKGROUND}

Chronic illnesses maimed the caretaker-adults much more than the children as Children are seen as extensions of the self. Apart from the emotional consequences, loss of working hours and income, the effect of childhood cancer is more pervasive and profound. It confronts the child and the family with a new reality, one that includes the physical aspect (hospital, doctor, chemotherapy) and the psychological one (trauma, change, and grief). The ability of the child and the

'Financial or Other Competing Interest': None.

Submission 10-09-2017, Peer Review 12-10-2017,

Acceptance 19-10-2017, Published 26-10-2017.

Corresponding Author:

Dr. S. Ananda Krishna Kumar,

Plot No. 14, Muthamil Nagar,

$3^{\text {rd }}$ Street, P \& T Nagar, Madurai- 625017.

E-mail:dr.anandakrish@gmail.com

DOI: $10.14260 /$ jemds/2017/1293 family to adapt to this new reality and the consequential life altering changes has a tremendous effect on the course of treatment.

\section{Acute Lymphoblastic Leukaemia}

Acute leukaemia, especially Acute Lymphoblastic Leukaemia (henceforth referred as ALL), is the most common form of malignancy in childhood with a peak incidence between 2 and 6 years of age and common in boys. The most stressful periods in the management include the time of diagnosis, remission during the longterm survival and death.

\section{Psychopathology of Parents of Children with ALL}

Parents of children with longterm illnesses are under greater strain than other families.[1] The diagnosis of chronic illness results in an overwhelming number of intense emotions and negatively impact upon the parents, financially and emotionally.[2] 
Studies on parents of children with cancer have reported the presence of prominence of psychopathology, particularly depression in up to $85 \%$ of the parents. [3][4] Parents also reported poor sexual and marital adjustment. ${ }^{[4]}$ Magni ${ }^{[5]}$ found that psychological distress of the mothers was negatively correlated with their child's adjustment to the disease. Another study on depression of parents of children has shown that depression was found in $56.7 \%$ of the parents.[6] Fatiadou[7] reported that more than one third of the parents in their study had psychiatric disorders.

\section{Individual and Family}

Research has shown that individuals use multiple coping strategies in any given situation. ${ }^{[8]}$ When individuals appraise the situation as being changeable or within their control, they use problem-focused coping styles ${ }^{[9]}$ and where the situation is perceived as out of control, they use emotion focused strategies.

In Koocher and O'Malley's[10] study, patient variables related to better adjustment and coping were young age at diagnosis, early knowledge of diagnosis and good self-esteem. A cross-sectional investigation by Brown ${ }^{[11]}$ revealed coping strategies commonly used by children and their parents which include problem-solving, a positive outlook, and good communication. A study by Goldbeck ${ }^{[12]}$ showed that the dominant coping styles used were problem-focused coping strategies in combination with optimistic basic attitude. Patistea[13] explored how parents perceived the child's leukaemia and found most of the participants perceived the child's disease as a serious and threatening situation. Sharan [14] studied the coping and adaptations of parents found that only $37 \%$ maintained an expectation of a positive outcome. Coping strategies were variable and not significantly correlated with coping adequacy or adjustment.[15] These studies underscore the importance of early assessment and correction of maladaptive coping styles of parents. Parental distress specific to invasive procedures remained relatively high and constant over the 2 to 3 years of treatment.[16] While the reduction of pain and anxiety during the procedures has been a successful area of psychological intervention, procedures continued to be among the most frequently distressing memories reported by survivors and their parents and produce posttraumatic stress symptoms.[17]

Children with cancer and their parents experienced significantly more emotional distress than children and parents in the community.[18] A followup study showed that higher level of parenting stress during treatment was associated with higher state anxiety after the child completed treatment and a significant association with post-traumatic stress.[19] These studies suggest that evaluation of parenting stress early in the illness course and appropriate treatment lead a better quality of life.[17]

\section{MATERIALS AND METHODS}

Aim- The present study aims to assess the psychopathology among the parents of children with ALL, their Family burden, Quality of life, stressful life events and coping and to infer their possible predictors.

\section{Objectives}

1 To assess the frequency of psychopathology and psychiatric disorders among the parents of children with ALL.
2 To know the type of coping strategies used by the parents and their associations with psychopathology and quality of life.

3 To study the quality of life of the parents and their associations with psychopathology and coping strategies.

4 To understand the family burden, stressful life events and their associations with psychopathology and quality of life.

\section{Hypotheses}

The following Hypotheses were Formulated-

1 Parents of children with ALL are more prone to psychiatric disorders.

2 Anxiety disorders are the most common among their parents.

3 Longer duration of illness and development of side effects in treatment is associated with more Psychopathology and poor Quality of life in parents.

4 The presence of stressful life events increases the risk of psychiatric disturbances and results in poor Quality of life in parents.

5 Psychopathology will be lesser and the quality of life may be better in parents who use a more adaptive way of coping.

6 The presence of stressful life events and psychiatric disturbances interferes with Family relationships and Family dynamics.

\section{Research Design}

The study was conducted in the Department of Paediatrics, Govt. Rajaji Hospital, Madurai with approval of the Institutional Ethics Committee during a period of six months from December 2007 to May 2008. The study was a crosssectional evaluation of the psychological functioning of the parents of children with ALL and the study population included 30 parents of children with a diagnosis of Acute Lymphoblastic Leukaemia. The diagnosis was established on the basis of clinical and laboratory investigations by the Paediatric Consultant. The subjects were recruited randomly based on the following selection criteria.

\section{Inclusion Criteria}

1. Parents of Children with a diagnosis of ALL, during their hospital stay for chemotherapy. 2. Parents of Children between 5 and 12 years of age. 3 . At least one parent who is available throughout the assessments. 4. Parents who consent to participate.

\section{Exclusion Criteria}

1. Parents of Children with previous history of psychological morbidity such as mental retardation. 2. Parents of Children with history of other medical illnesses. 3. Family history of any other significant physical or psychological morbidity. 4. Very sick children.

\section{Operational Design}

Considering due allowance for the ethnical variation, a pilot study was conducted and after a brief familiarising session and knowing details of the illness and of the family, a written consent was obtained from the parents. One of the parents of 
child with ALL was assessed and the following instruments were administered.

Tools employed: 1. A Semi-structured Proforma: Compiled for recording sociodemographic variables, medical history and details of illness. 2. General health questionnaire - 28[20]: It contains 28 items with four subscales, each containing seven items. It is used to diagnose Psychiatric disorders in General population and Community. 3. Quality of life scale - WHO QOL - BREF[21]: It contains 26 items rated on a five-point scale with excellent reliability. 4. Presumptive stressful life events scale[22]: It contains 51 items prepared for adult Indian population with reliability of 0.73. 5. Family burden interview schedule[23]: A tool to measure social burden on the Family of Parents, measuring on seven subscales with three-point scale of severity. 6. Ways of Coping (revised) ${ }^{[24]}$ : It has a 66-item questionnaire responding to demands of stressful encounters on a 4-point Likert scale. 7. ICD 10[25]: It is a classification code set developed by WHO.

\section{Statistical Analysis}

Analysis of the data was done using the measures of central tendency and dispersion. The associations between the variables were analysed using Pearson's correlation.

\section{RESULTS}

\begin{tabular}{|c|c|c|c|c|}
\hline Variable & Mean & SD & $\begin{array}{c}\text { Range } \\
\text { Max-min }\end{array}$ & $\begin{array}{c}\text { Parents above } \\
\text { cut off Value } \\
\text { No (\%) }\end{array}$ \\
\hline GHQ & 46.43 & 9.89 & $28-71$ & $30(100)$ \\
\hline $\begin{array}{c}\text { Overall Quality } \\
\text { of Life }\end{array}$ & 4.80 & 1.16 & $4-6$ & - \\
\hline Physical Health & 43.47 & 10.61 & $17-57$ & $27(90)$ \\
\hline $\begin{array}{c}\text { Psychological } \\
\text { Health }\end{array}$ & 26.43 & 5.72 & $12-38$ & $21(70)$ \\
\hline Social Relations & 35.73 & 12.26 & $8-50$ & $28(93)$ \\
\hline Environment & 39.00 & 6.88 & $28-50$ & $25(83)$ \\
\hline PSLES & 141.73 & 48.31 & $54-273$ & - \\
\hline Family Burden & 25.43 & 7.66 & $12-45$ & - \\
\hline Coping & 59.83 & 9.49 & $32-76$ & - \\
\hline \multicolumn{4}{|c|}{$\begin{array}{c}\text { Table 1. Measures of the Variables } \\
\text { of Psychopathology of Parents }\end{array}$} \\
\hline
\end{tabular}

Cut-off Scores-

GHQ- General Health Questionnaire- 24

Overall Quality of Life-

Physical Health-

28

Psychological Health- $\quad 24$

Social Relationships- 12

Environment- 32

PSLES- Presumptive stressful life events scale.

It was observed that all the parents had significant psychological problems as indicated by the scores on GHQ. However, nearly $80-90 \%$ of them were found to have a better quality of life.

\section{ICD 10 Diagnosis}

Persistent somatoform pain disorder (F45.4) was diagnosed in 4 of the parents and 9 of them met criteria for Adjustment disorder with depressed mood (F43.2).

\begin{tabular}{|l|c|c|c|c|c|c|c|}
\hline Variable & GHQ & $\begin{array}{c}\text { OV } \\
\text { QOL }\end{array}$ & PH & PS H & SO RE & ENV & PSLES \\
\hline $\begin{array}{c}\text { Duration } \\
\text { of Illness }\end{array}$ & 0.09 & -0.34 & -0.22 & -0.24 & -0.14 & -0.18 & -0.02 \\
\hline Side Effect & 0.25 & $-0.38^{*}$ & -0.21 & -0.21 & -0.13 & -0.25 & 0.33 \\
\hline $\begin{array}{c}\text { Treatment } \\
\text { Phase }\end{array}$ & $0.46^{* *}$ & -0.35 & -0.29 & $-0.37^{*}$ & -0.07 & -0.33 & 0.29 \\
\hline
\end{tabular}

Table 2. Correlations between Measures of Psychological Morbidity among Parents and Disease Variables

Values refer to Pearson's $\mathrm{r}$ $\mathrm{Df}=28 ; \mathrm{p}<0.05^{*} ; \mathrm{p}<0.01^{* *}$

GHQ - General Health Questionnaire, OV QOL - overall quality of life, PH - Physical health, PS H - Psychological health, SO RE- Social relationships, ENV - Environment, PSLES- Presumptive stressful life events scale.

Correlations of the parent psychopathology and the disease variables indicated that, the treatment phase correlated positively with the GHQ and negatively with psychological health domain of QOL. It was also observed that, the presence of side-effects correlated negatively with the overall QOL.

\begin{tabular}{|c|c|c|c|c|c|c|c|}
\hline & GHQ & OV QOL & PHY H & PSY H & SO RE & ENV & PSLES \\
\hline GHQ & - & $-0.72^{* *}$ & $-0.77^{* *}$ & $-0.64^{* *}$ & $-0.46^{* *}$ & $-0.61^{* *}$ & $0.38^{*}$ \\
\hline Overall QOL & $-0.72^{* *}$ & - & $0.76^{* *}$ & $0.59^{* *}$ & $0.55^{* *}$ & $0.71^{* *}$ & $-0.49^{* *}$ \\
\hline Physical Health & $-0.77^{* *}$ & $0.76^{* *}$ & - & $0.70^{* *}$ & 0.32 & $0.40^{*}$ & -0.35 \\
\hline $\begin{array}{c}\text { Psychological } \\
\text { Health }\end{array}$ & $-0.64^{* *}$ & $0.59^{* *}$ & $0.70^{* *}$ & - & 0.17 & 0.33 & -0.01 \\
\hline $\begin{array}{c}\text { Social } \\
\text { Relationship }\end{array}$ & $-0.46^{* *}$ & $0.55^{* *}$ & 0.32 & 0.17 & - & $0.69^{* *}$ & $-0.50^{* *}$ \\
\hline Environment & $-0.61^{* *}$ & $0.71^{* *}$ & $0.40^{*}$ & 0.33 & $0.69^{* *}$ & - & $-0.37^{*}$ \\
\hline PSLES & $0.38^{*}$ & $-0.49^{* *}$ & -0.35 & -0.01 & $-0.50^{* *}$ & $-0.37^{*}$ & - \\
\hline \multicolumn{7}{|c|}{ Table 3. Correlations between Measures of } \\
Psychological Morbidity among Parents
\end{tabular}

Values refer to Pearson's $r$ $\mathrm{Df}=28 ; \mathrm{p}<0.05^{*} ; \mathrm{p}<0.01^{* *}$

GHQ- General Health Questionnaire, PSY H- Psychological health, OV QOL- overall quality of life, SO RE- Social relationships, PHY H- Physical health, ENV- Environment, PSLES- Presumptive stressful life events scale.

Correlation between measures of psychological morbidity among the parents indicates significant association with Positive correlation exists between the scores in GHQ and PSLES. Negative correlations were observed between the overall QOL and the scores in GHQ and PSLES, indicating that the presence of psychopathology and stressful life events significantly affected the quality of life. Negative correlation also exists between the various domains of QOL with GHQ and PSLES. Also significant positive correlations exist among the various domains of QOL. 


\begin{tabular}{|c|c|c|c|c|c|c|c|}
\hline & FB & FR & FL & FI & PHY H & PSY H & SB \\
\hline GHQ & 0.29 & $0.40^{*}$ & $0.36^{*}$ & $0.63^{* *}$ & $0.55^{* *}$ & $0.48^{* *}$ & $0.47^{* *}$ \\
\hline $\begin{array}{c}\text { Overall } \\
\text { Quality of Life }\end{array}$ & $-0.38^{*}$ & $-0.55^{* *}$ & $-0.43^{*}$ & $-0.58^{* *}$ & $-0.57^{* *}$ & $-0.44^{*}$ & $-0.40^{*}$ \\
\hline $\begin{array}{c}\text { Physical } \\
\text { Health }\end{array}$ & -0.19 & $-0.38^{*}$ & -0.18 & $-0.48^{* *}$ & $-0.41^{*}$ & -0.34 & -0.33 \\
\hline $\begin{array}{c}\text { Psychological } \\
\text { Health }\end{array}$ & -0.25 & -0.12 & -0.09 & -0.14 & -0.11 & -0.00 & -0.11 \\
\hline $\begin{array}{c}\text { Social } \\
\text { Relationships }\end{array}$ & $-0.56^{* *}$ & $-0.66^{* *}$ & $-0.58^{* *}$ & $-0.66^{* *}$ & $-0.62^{* *}$ & $-0.56^{* *}$ & -0.33 \\
\hline Environment & $-0.54^{* *}$ & $-0.54^{* *}$ & $-0.62^{* *}$ & $-0.60^{* *}$ & $-0.51^{* *}$ & $-0.41^{*}$ & $-0.51^{* *}$ \\
\hline PSLES & 0.08 & $0.58^{* *}$ & $0.43^{*}$ & $0.52^{* *}$ & $0.52^{* *}$ & $0.45^{*}$ & $0.43^{*}$ \\
\hline Table 4. Corretion & &
\end{tabular}

Table 4. Correlations between Measures of Psychological Morbidity among Parents and Family Burden

Values refer to Pearson's $r$

$\mathrm{Df}=28 ; \mathrm{p}<0.05^{*} ; \mathrm{p}<0.01^{* *}$

GHQ- General Health Questionnaire, PSY H- Psychological health, OV QOL- Overall quality of life, SO RE- Social relationships, PHY H- Physical health, ENV- Environment, PSLES- Presumptive stressful life events scale, FB- Financial burden, FR- Family routine, FL- Family leisure, FI- Family interaction, PH- Physical health, PS H- Psychological health SB- Subjective burden.

Correlations between the measures of parent's psychopathology and Family burden indicate that, significant positive correlation exists between GHQ, PSLES and Family routine, Family leisure, Family interaction, Physical health, Mental health and the Subjective burden. The Financial burden of the family correlated negatively with overall QOL, social relationships and Environment domain of QOL. The physical health domain on QOL correlated negatively with family routine, family interaction and physical health of family members. The social relationships and environment domain of QOL correlated negatively with family routine, leisure, interaction, physical and mental health of the family members.

\begin{tabular}{|c|c|c|c|c|c|c|c|c|}
\hline & CONF & DIST & \begin{tabular}{|l|} 
SELF \\
CONT
\end{tabular} & \begin{tabular}{|l|} 
SOCIAL \\
SUPP
\end{tabular} & \begin{tabular}{|c|} 
ACC \\
RESP \\
\end{tabular} & \begin{tabular}{|c|} 
ESC \\
AVD
\end{tabular} & $\begin{array}{l}\text { PLAN } \\
\text { PROB }\end{array}$ & \begin{tabular}{|c|} 
POSI \\
REAPP
\end{tabular} \\
\hline GHQ & 50.18 & 0.25 & \begin{tabular}{|l|}
0.11 \\
\end{tabular} & 0.07 & \begin{tabular}{|l|}
-0.01 \\
\end{tabular} & \begin{tabular}{|l|}
0.31 \\
\end{tabular} & \begin{tabular}{|l|}
0.13 \\
\end{tabular} & \begin{tabular}{|l|}
0.11 \\
\end{tabular} \\
\hline \begin{tabular}{|c|} 
Overall \\
Quality of Life
\end{tabular} & -0.29 & -0.18 & $|-0.27|$ & 0.05 & 0.07 & $|-0.17|$ & -0.10 & -0.06 \\
\hline $\begin{array}{c}\text { Physical } \\
\text { Health }\end{array}$ & -0.10 & -0.20 & -0.11 & 0.18 & -0.03 & -0.29 & -0.13 & -0.03 \\
\hline $\begin{array}{c}\text { Psychological } \\
\text { Health }\end{array}$ & -0.16 & -0.10 & -0.05 & 0.15 & 0.05 & -0.01 & 0.03 & 0.05 \\
\hline \begin{tabular}{c|} 
Social \\
Relationships
\end{tabular} & -0.11 & $\begin{array}{c}- \\
0.36^{*}\end{array}$ & -0.06 & -0.11 & -0.08 & -0.13 & -0.25 & -0.12 \\
\hline Environment & -0.26 & -0.28 & $\mid-0.10$ & -0.16 & 0.09 & $|-0.23|$ & -0.10 & -0.02 \\
\hline PSLES & 0.19 & 0.19 & \begin{tabular}{|l|}
0.29 \\
\end{tabular} & -0.05 & 0.07 & \begin{tabular}{|l|}
0.01 \\
\end{tabular} & 0.07 & 0.10 \\
\hline
\end{tabular}

Values refer to Pearson's $\mathrm{r}$

$\mathrm{Df}=28 ; \mathrm{p}<0.05^{*} ; \mathrm{p}<0.01^{* *}$

GHQ- General Health Questionnaire, Over QOL- overall quality of life, PHY Health- Physical health, PSY HealthPsychological health, Social Relation- Social relationships, ENVIRON- Environment, PSLES- Presumptive stressful life events scale. CONF-Confronting, DIST- Distancing, SC-Selfcontrolling, SS- Social Support, AR-Accepting responsibility,
EA-Escape avoidance PP-Planful problem solving, PR-Positive reappraisal.

Correlations between the psychopathology of the parents and their coping skills showed that, those who used distancing as a coping strategy found their social relationships to be poor, as indicated by the negative correlation between the two.

\begin{tabular}{|c|c|c|c|c|c|c|c|c|}
\hline & CONF & DIST & SC & SS & AR & EA & PP & PR \\
\hline FB & 0.20 & $0.37^{*}$ & 0.12 & $0.50^{* *}$ & 0.15 & 0.22 & $0.43^{*}$ & $0.43^{*}$ \\
\hline FR & $0.37^{*}$ & $0.41^{*}$ & $0.39^{*}$ & 0.30 & 0.25 & 0.03 & $0.39^{*}$ & $0.47^{* *}$ \\
\hline FL & $0.53^{* *}$ & $0.53^{* *}$ & $0.52^{* *}$ & $0.60^{* *}$ & 0.24 & 0.22 & $0.46^{* *}$ & $0.52^{* *}$ \\
\hline FI & 0.23 & 0.33 & 0.27 & 0.18 & 0.26 & 0.33 & 0.25 & 0.27 \\
\hline PH & 0.18 & $0.42^{*}$ & 0.34 & 0.20 & 0.27 & 0.31 & 0.33 & 0.31 \\
\hline $\begin{array}{c}\text { PS } \\
\text { H }\end{array}$ & 0.19 & $0.45^{*}$ & $0.37^{*}$ & 0.27 & 0.34 & 0.27 & 0.32 & 0.30 \\
\hline SB & $0.39^{*}$ & $0.41^{*}$ & $0.39^{*}$ & $0.47^{* *}$ & 0.16 & $0.36^{*}$ & 0.26 & $0.36^{*}$ \\
\hline \multicolumn{8}{|c|}{ Table 6. Correlations between Measures } \\
of Family Burden and Coping \\
\hline
\end{tabular}

Values refer to Pearson's $\mathrm{r}$

$\mathrm{Df}=28 ; \mathrm{p}<0.05^{*} ; \mathrm{p}<0.01^{* *}$

FB- Financial burden, CONF -Confronting, FR- Family routine, DIST -Distancing, FL- Family leisure, SC -Self controlling, FI- Family interaction, SS -Social support, $\mathrm{PH}-$ Physical health, AR -Accepting responsibility, PS $\mathrm{H}-$ Psychological health, EA-Escape avoidance, SB- Subjective burden, PP-Planful problem solving, PR-Positive reappraisal.

Significant positive correlations were observed between financial burden and distancing, social support seeking, planful problem solving and positive reappraisal. The family routine and leisure correlated positively with confronting, distancing, self-controlling, planful problem solving and positive reappraisal. In addition, the family leisure correlated significantly with social support seeking. Family interaction did not correlate significantly with any of the strategies. The mental health correlated with distancing, self-controlling, planful problem solving and positive reappraisal. The subjective burden correlated positively with all strategies except accepting responsibility and planful problem solving.

\section{DISCUSSION}

Leukaemia is a chronic illness. The tools used in the study were sought to understand and quantify both the distress and the extent of well-being experienced by their parents. To substantiate the clinical observation that the families were able to adapt well despite very severe stress, their methods of coping in the course of time were investigated using a 66item Likert-type scale.

The frequency of psychiatric disorders among half of the parents in our study indicated the extent of distress experienced which were lower in comparison to Magni[3] \& Maguire. ${ }^{[4]}$ Persistent Somatoform pain disorders in six parents and adjustment disorder with depressed mood in nine parents were the most common diagnoses which replicates study by Sharan. ${ }^{[26]}$ The distress was evident in the scores on various scales. Significance of the increased stressful life events was evident in our study which is similar to Varni.[1] In GHQ all the parents scored above the cut-off mark which is in agreement to study by Satterwhite, though significant numbers of them were found to evince a commendable quality of life in QOL scores. The results confirmed that though the parents were distressed 
enormously due to the illness of the child, they were able to effectively maintain their quality of life.

The psychological distress of the parents and the presence of other stressful life events significantly affected the family routine, the family interaction, the physical and mental health of the family members. The subjective burden on the family was thus found to be high which reflects the study by Magni[2] \& Sawyer.[7] This in turn affected the quality of life of the parents. The financial burden of the family was high when the environment and social relationships of the family was poor.

Psychopathology of the parents significantly affected their quality of life as indicated by the negative correlations between GHQ and the various domains of QOL. The presence of stressful life events significantly affected the parent's psychopathology and their quality of life as indicated by the positive correlations between PSLES and GHQ and negative correlations with all domains on QOL which were found by Satterwhite[2] \& Kazak.[9]

The family structure in our society, passed on from ancient times, was a definite asset in the adaptive measures exhibited by the parents of the cancer children in contrast to Western societies.[27] Even though most of the families in the study were from nuclear families, they were able to get the support of their relatives like spiritual and psychological support from grandparents. Three fifths of the parents were using problem-focused coping strategy, one third used emotion-focused coping and only $10 \%$ were using avoidant coping strategies like distancing and escape avoidance which were found by early Researchers. ${ }^{[8][9][15]}$ The financial burden of the family was increased when they were seeking social support in the form of professional help and when they were trying to solve the problem by one means or other. The family routine and leisure was affected when the parents were confronting the situation, or trying to control their emotions, or distancing themselves from the situation. The physical and psychological health of the parents was disturbed by distancing and self-controlling. Finally the subjective burden of the family was high when the families used emotionfocused coping strategies. Distress of the children is an essential and determining cause of parental distress, poor quality of life and family burden which also reflects previous findings.[16][17][18] On the other hand parental psychopathology affects their care giving abilities thereby affecting the children's well-being. Resilience of the parents in the face of distress comes out markedly in the study and the findings would guide the mental health professionals in positively managing the difficult Liaison-Psychiatry problem.

\section{CONCLUSION}

Based on the findings, the following conclusions are made. Parents of children with ALL are more prone to Psychiatric disorders. Adjustment disorders are the most common illness among the parents. Longer duration of illness in Children does not significantly increase Psychopathology in parents but development of side effects in treatment reduces overall Quality of life. The presence of stressful life events significantly increases the risk of Psychiatric disturbances and poor Quality of life in parents. Psychopathology and the quality of life do not show significant relationship with ways of coping except those who used distancing as a coping strategy found their social relationships to be poor. The presence of stressful life events and Psychiatric disturbances significantly interferes Family relationships, Family dynamics, Family interaction and Subjective Burden.

Appropriate Psychiatric intervention would reduce the psychiatric morbidity in these parents. Encouraging active coping strategies and replacing avoidant ones and providing them with the hope and courage to bear what is eventually an unavoidable problem would be of great help.

\section{REFERENCES}

[1] Varni JW, Katz ER, Colegrove R, et al. Family functioning predictors of adjustment in children with newly diagnosed cancer: a prospective analysis. J Child Psychol Psychiatry 1996;37(3):321-8.

[2] Satterwhite BB. Impact of chronic illness on child and family: an overview based on five surveys with implications for management. Int J Rehabil Res 1978;1(1):7-17.

[3] Magni G, Messina C, De Leo D, et al. Psychological distress in parents of children with acute lymphatic leukemia. Acta Psychiatr Scand 1983;68(4):297-300.

[4] Maguire GP. Psychological consequences of childhood leukaemia. J R Soc Med 1980;73(3):217-8.

[5] Magni G, Silvestro A, Tamiello M, et al. An integrated approach to the assessment of family adjustment to acute lymphocytic leukemia in children. Acta Psychiatr Scand 1988;78(5):639-42.

[6] Iqbal A, Siddiqui KS. Depression among parents of children with acute lymphoblastic leukemia. J Ayub Med Coll Abbottabad 2002;14(2):6-9.

[7] Fotiadou M, Barlow JH, Powell LA, et al. Optimism and psychological well-being among parents of children with cancer: an exploratory study. Psycho-Oncology 2008;17(4):401-9.

[8] Lazarus RS. Hope: an emotion and a vital coping resource against despair. Social Research 1999;66(2):653-78.

[9] Schüssler G. Coping strategies and individual meanings of illness. Soc Sci Med 1992;34(4):427-32.

[10] O'Malley JE, Koocher G, Foster D, et al. Psychiatric sequelae of surviving childhood cancer. Am J Orthopsychiatry 1979;49(4):608-16.

[11] Brown RT, Kaslow NJ, Hazzard AP, et al. Psychiatric and family functioning in children with leukemia and their parents. J Am Acad Child Adolesc Psychiatry 1992;31(3):495-502.

[12] Goldbeck L. Familial coping with cancer in childhood and adolescence. Possibilities for standardized assessment with a self-assessment method: results of an empirical pilot study. Prax Kinderpsychol Kinderpsychiatr 1998;47(8):552-73.

[13] Patistea E. Description and adequacy of parental coping behaviours in childhood leukaemia. Int J Nurs Stud 2005;42(3):283-96.

[14] Sharan P, Mehta M, Choudhry VP. Coping and adaptation in parents of children suffering from acute lymphoblastic leukemia. Indian J Pediatr 1995;62(6):737-41.

[15] Kupst MJ, Natta MB, Richardson CC, et al. Family coping with pediatric leukemia: ten years after treatment. J Pediatr Psychol 1995;20(5):601-17. 
[16] Kazak AE, Boyer BA, Brophy P, et al. Parental perceptions of procedure-related distress and family adaptation in childhood leukemia. Child Health Care 1995;24(3):143-58.

[17] Kazak AE, Barakat LP. Brief report: parenting stress and quality of life during treatment for childhood leukemia predicts child and parent adjustment after treatment ends. J Pediatr Psychol 1997;22(5):749-58.

[18] Sawyer M, Antoniou G, Toogood I, et al. Childhood cancer: a two-year prospective study of the psychological adjustment of children and parents. J Am Acad Child Adolesc Psychiatry 1997;36(12):173643.

[19] Kazak AE, Baxt C. Families of infants and young children with cancer: a post-traumatic stress framework. Pediatric Blood Cancer 2007;49(7 Suppl):1109-13.

[20] Goldberg, David P. A user's guide to the General Health Questionnaire. David Goldberg and Paul Williams. Book edn. Windsor, Berks. : NFER-Nelson, 1988:pp 129.

[21] World Health Organization. WHO quality of life-bref (WHOQOL-BREF). 2004 [2009--09--10]. http.//www, who. int/substance-abuse/researchtools/ whoqolbref/en. 2012
[22] Singh G, Kaur D, Kaur H. Presumptive stressful life events scale (PSLES)-a new stressful life events scale for use in India. Indian J Psychiatry 1984;26(2):10714.

[23] Pai S, Kapur RL. The burden on the family of a psychiatric patient: development of an interview schedule. Br J Psychiatry 1981;138(4):332-5.

[24] Folkman S, Lazarus RS, Gruen RJ, et al. Appraisal, coping, health status, and psychological symptoms. J Pers Soc Psychol 1986;50(3):571-9.

[25] World Health Organization. The ICD-10 classification of mental and behavioural disorders: clinical descriptions and diagnostic guidelines. Geneva: World Health Organization; 1992.

[26] Sharan P, Mehta M, Chaudhry VP. Psychiatric morbidity in children suffering from acute lymphoblastic leukemia. Pediatr Hematol Oncol 1999;16(1):49-54.

[27] Rajajee S, Ezhilarasi S, Indumathi D. Psychosocial problems in families of children with cancer. Indian J Pediatr 2007;74(9):837-9. 